\title{
Area Requirement based Load Frequency Controller using Artificial Bee Colony Algorithm for a Two Area Interconnected Power System with GT Unit
}

\author{
P.Venkatasubramanian \\ Assistant Professor \\ Department of Electrical Engineering \\ Annamalai University, Annamalai \\ Nagar \\ Tamil nadu, India, Pin-608002.
}

\author{
S.Abraham Lincon, PhD. \\ Professor \\ Department of Instrumentation \\ Engineering, \\ Annamalai University, Annamalai Nagar, \\ Tamil nadu, India, Pin-608002.
}

\begin{abstract}
This paper proposes a design of Artificial Bee Colony (ABC) algorithm based Proportional plus Integral controller using Area Requirement (AR) Criterion for the Load Frequency Control of a two area multi unit interconnected thermal reheat power system without and with Gas Turbine unit. The system was simulated and the output responses of the frequency deviations, tie-line power deviation and control input deviations for $1 \%$ step load disturbance in area 1 were obtained. The simulations results reveals that the two area multi unit interconnected thermal reheat power system incorporated with Gas Turbine unit ensure a better transient response and smaller settling time.
\end{abstract}

\section{Key words}

Artifical Bee Colony, Proportional - Intergral controller, Area Requirement criterion, Load-Frequency Control

\section{INTRODUCTION}

In the power system operation and control the main constraints to be satisfied is to maintain the system frequency and terminal voltages within the specified limits. The power system should not only ensure a better quality but also reliable power supply by maintaining the above mentioned constraints. According to power system control theory, a nominal system frequency depends on the balance between generated and consumed real power [1]. If the amount of generated power is less than the demanded amount, speed and frequency of the generator units begin to decrease, and vice versa. Hence, the amount of power produced by each generators should take care in minimizing the frequency deviations occurred in the power system due to sudden change in load. For this purpose, load frequency control is being adopted and the main aim of this control is that the steady state error of the system frequency deviations following a step load demand should be made zero in a faster manner. The stabilization of frequency oscillations in an interconnected power system becomes challenging when implemented in the future environment due to unpredictable load demand. So advance economic, high efficiency and improved control schemes [2, 3] are required to ensure the power system reliability. Several indices have been proposed as methods to evaluates the success of frequency control between linked systems. For instance, the AR based standard deviations are very popular in Europe and United States and are adopted as indices $[4,5]$. The accurate measured values of the frequency in each system and operating line flows are used for calculating such indices. In particular, this is the case for their dynamic behavior against random load disturbance. Gas Turbine (GT) units with a maximum capacity can be applied not only as a fast energy compensation device for large loads but also to damp out the frequency and tie-line deviations, which makes it a cost-effective system [6-9]. Moreover GT becomes increasingly popular in different power scenario due to their green house emission as well as higher efficiency especially when connected in a Combined Cycle power plant [6].

Most of the conventional methods based optimization for tuning the controller gains is a trial and error method and is found to be extremely time consuming if several parameters have to be optimized simultaneously and provides suboptimal result. Most of the classical optimization techniques need detailed information about the objective function to design efficient controllers. Heuristic Techniques like Genetic Algorithm(GA), GA combined with Simulated Annealing(SA), Evolutionary Programming, Particle Swarm Optimization(PSO) techniques have been used to solve the optimization problems. Amongst the population based algorithms, SA suffers from settings of algorithm parameters and gives rise to repeat revisiting of the same suboptimal solutions. The GA method is usually faster than SA method because GA has parallel search technique [10]. Some authors have applied GA/PSO technique to optimize controller gains more effectively and efficiently than the classical approach. Recent research has brought out some deficiencies in GA/PSO performance [11]. The premature convergence of GA/PSO degrades its search capability [12]. This paper proposes an effective new optimization approach, to solve the LoadFrequency control (LFC) problem using Artificial Bee Colony (ABC) algorithm. The Artificial Bee Colony algorithm, a new swarm intelligent algorithm, was proposed by Karaboga [13] is widely used since the $\mathrm{ABC}$ algorithm is simple in concept, easy to implement, has fewer control parameters, and so it has been used in many fields even for unconstrained optimization problems [14, 15]. As ABC algorithms are highly robust yet remarkably simple to implement it is quite pertinent to apply the $\mathrm{ABC}$, with no more new modifications, to achieve better optimization for the Load 


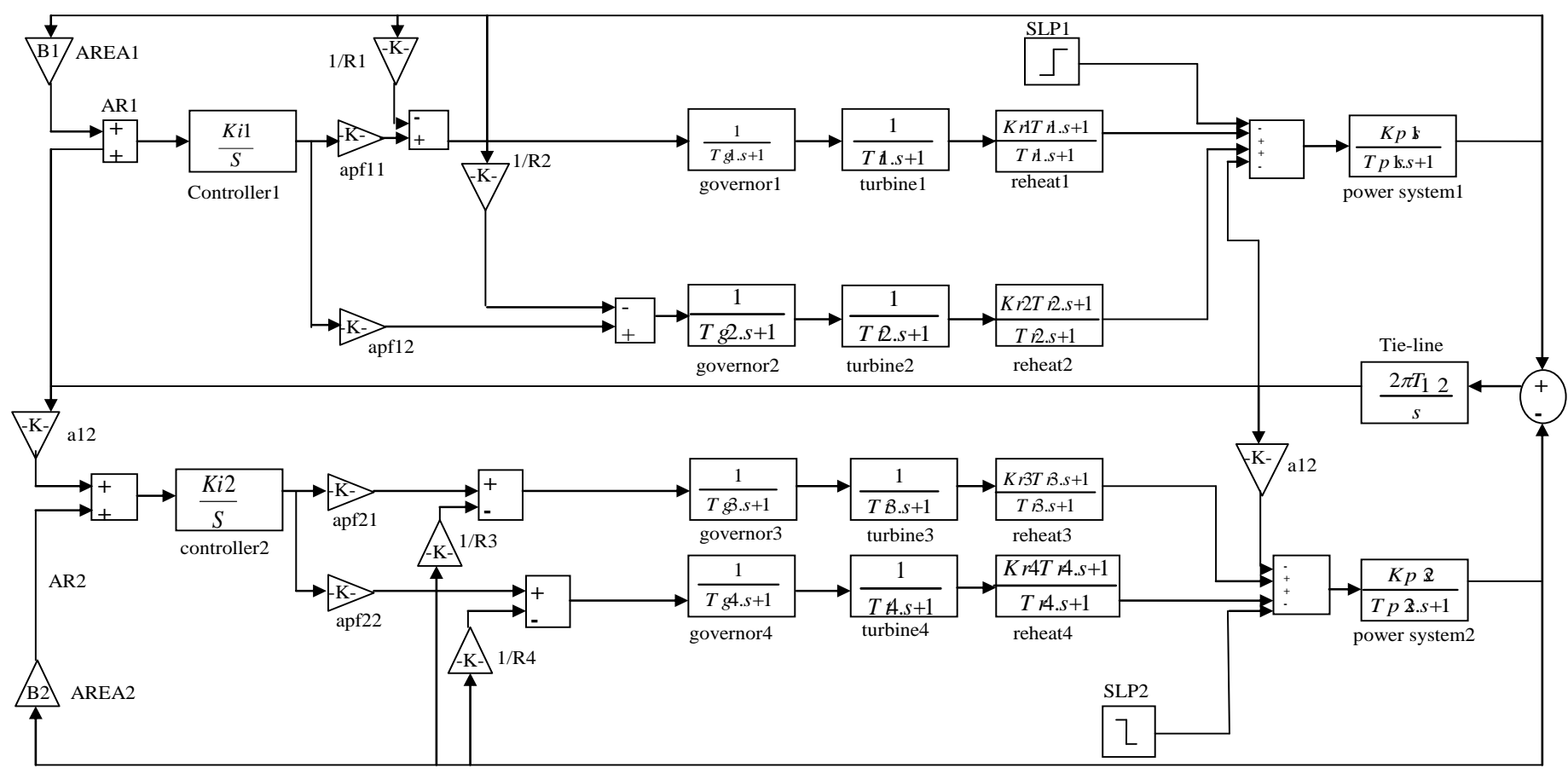

Fig 1 .Simulink model of two- area interconnected thermal reheat power system

Frequency Control problems more efficiently. In this study, $\mathrm{ABC}$ algorithm is used for optimizing the Proportional plus Integral controller gains for the load frequency control of a two area thermal power system without and with GT units. To obtain the best convergence performance, new cost function i.e. based on Area Requirement which is derived using the tieline power and frequency deviations of the control areas and their rates of changes according to time integral. The simulation results show that the dynamic performance of the system with GT unit is improved with the proposed controller.

\section{PROBLEM FORMULATION}

The state variable equation of the minimum realization model of $N$ area interconnected power system may be expressed as [16].

$$
\begin{aligned}
& \dot{x}=A x+B u+\Gamma d \\
& y=C x \\
& \text { Where } x=\left[x_{1}^{T}, \Delta p_{e i} \ldots x_{(N-1)}^{T}, \Delta p_{e(N-1)} \ldots x_{N}^{T}\right]^{T} \\
& \quad \text { n- State vector } \\
& n=\sum_{i=1}^{N} n_{i}+(N-1) \\
& u=\left[u_{1}, \ldots u_{N}\right]^{T}=\left[\Delta P_{C 1} \ldots P_{C N}\right]^{T}
\end{aligned}
$$

N-Control Input vector

$$
d=\left[d_{1}, \ldots d_{N}\right]^{T}=\left[\Delta P_{D 1} \ldots P_{D N}\right]^{T}
$$

N-Disturbance Input vector

$$
y=\left[y_{1} \ldots y_{N}\right]^{T} 2 \mathrm{~N}-\text { Measurable output vector }
$$

where $\mathrm{A}$ is system matrix, $\mathrm{B}$ is the input distribution matrix, $\Gamma$ is the disturbance distribution matrix, $\mathrm{C}$ is the control output distribution matrix, $\mathrm{x}$ is the state vector, $\mathrm{u}$ is the control vector and $\mathrm{d}$ is the disturbance vector consisting of load changes.

\section{TWO-AREA TWO-UNIT INTER CONNECTED THERMAL REHEAT POWER SYSTEM MODEL.}

Investigations have been carried out for a Two-area, Two-unit Interconnected Thermal Reheat Power System by considering a step load disturbance of $1 \%$ in area 1 .

\subsection{Modeling of a Gas Turbine unit}

To ensure a better quality and higher reliable Power supply to the $\mathrm{c}_{\frac{k_{1}}{s}}$;umers, the control input requirements has to be compensated with Distributed Generators(DG) to enhance zero frequency deviations, zero tie-line power deviat ns in a faster manner. Gas Turbines which is considered as c a of the DGs have higher efficiency and the lower green house emissions compared to other energy 


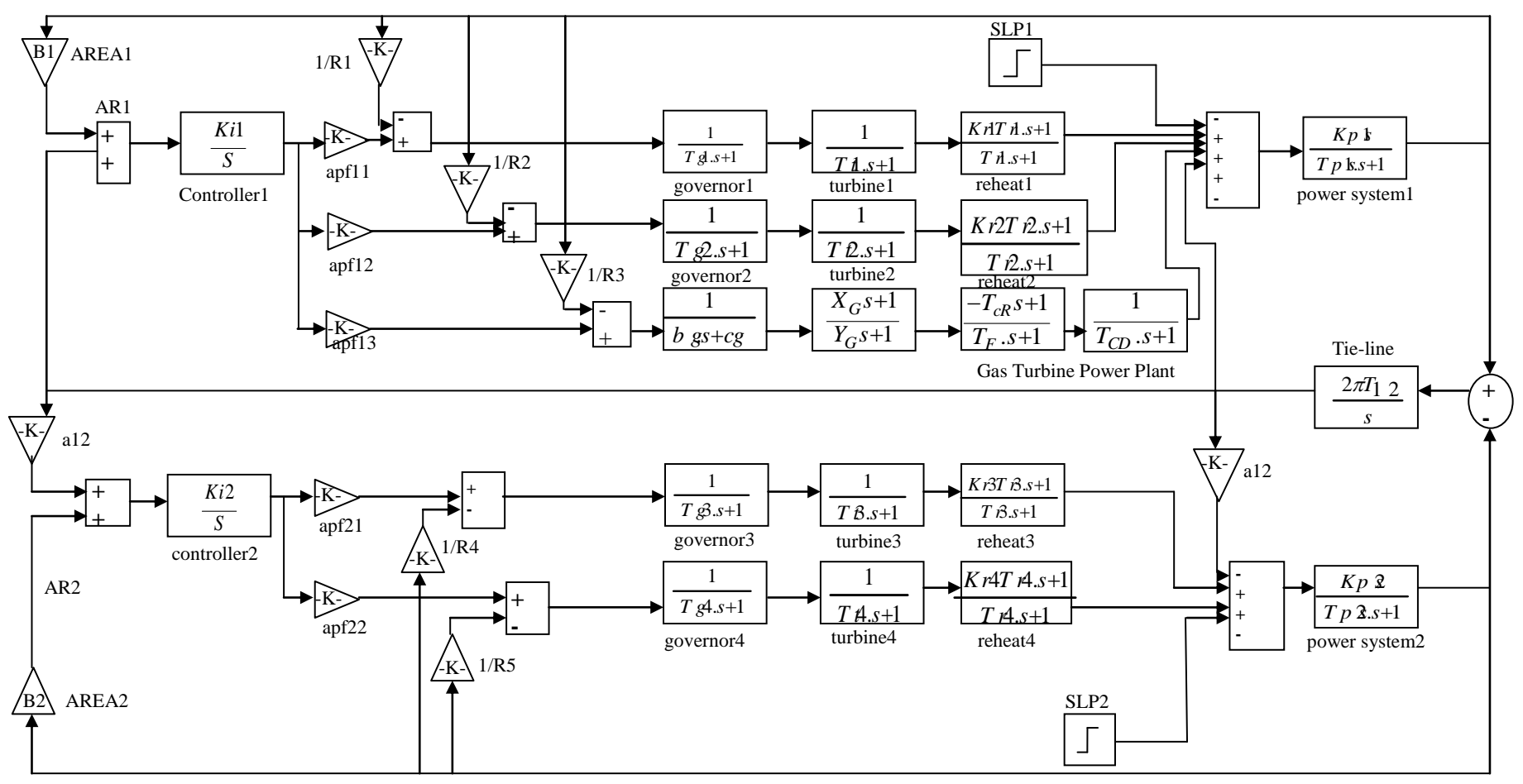

Fig 3.Simulink model of two- area interconnected thermal reheat power system with GT unit

sources and fast starting capability which enables them to be used even as peaking units that respond to peak demands. Many models representing the gas turbines have been developed over the years.

A Gas Turbine units transfer function model is shown in figure 2 which is one of the most commonly used dynamic models and has also been used in this methodology. Gas Turbines have the advantages like Quick start-up/shut-down, low weight and size, cost of installation is less, low capital cost, Black-start capability, high efficiency requires less cranking power, pollutant emission control etc., When the load is suddenly increased the speed drops quickly but the regulator reacts and increases the fuel flow to a maximum of $100 \%$, thereby improving the efficiency of the system [6].

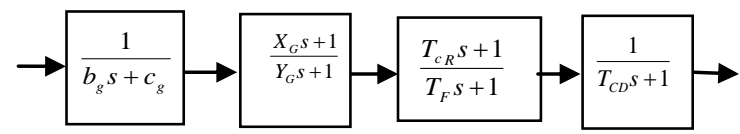

Fig.2. Transfer Function representation of a Gas Turbine Unit

\subsection{Application of Gas Turbine unit in Two- area, Two-unit interconnected Reheat Thermal Power System}

Investigations have been carried out for a Two-area, Two-unit Interconnected Thermal Reheat Power System with GT unit by considering a step load disturbance of $1 \%$ in area 1 .

\subsection{Design of the Proportional plus Integral Controller using Area Requirement (AR) based Criterion}

Recently, the evaluation of control performances of Interconnected Power System has become an important issue with respect to the individual load-frequency controllers. Several performance measures are in practice like Area control Error (ACE), Mutual Aid criterion (MAC) and Control Performance Standards (CPS).

In this paper, the Area Requirement (AR) for region " $i$ " is represented by $\Delta \mathrm{R}_{\mathrm{i}}$

$$
\Delta A R_{i}=-\Delta \mathrm{P}_{\mathrm{Ti}}-\mathrm{K}_{\mathrm{ARi}} \Delta F_{\mathrm{i}}
$$

Here, $\Delta \mathrm{P}_{\mathrm{Ti}}$ represents the sum of the tie-line flow sending from system $i$ to the connected systems, $K_{A R i}$ represents the frequency bias coefficient which is used to convert the frequency deviation into the electric power capacity, and $\Delta \mathrm{F}_{\mathrm{i}}$ represents the frequency deviation and $\mathrm{P}_{\mathrm{ELDi}}$ represents the total for the command values for economic load distribution and $\mathrm{P}_{\mathrm{Di}}$ is the load variation. $\Delta \mathrm{R}_{\mathrm{i}}$ in Eq. (4) represents an instantaneous supply/demand imbalance in region $\mathrm{i}$ and is used as an LFC performance measure by observing this over time, calculating the standard deviation, and performing statistical processing. 


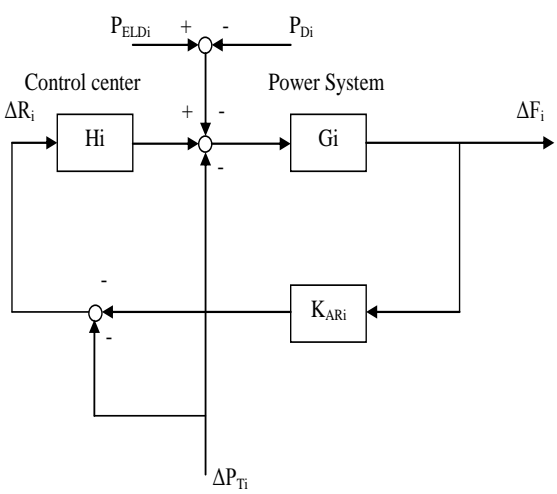

Fig 4. Schematic diagram representing $i^{\text {th }}$ area's Area Requirement

In this approach the two-area system is considered with the following transfer function matrix

$$
\left[\begin{array}{l}
\Delta A R_{1} \\
\Delta A R_{2}
\end{array}\right]=\left[\begin{array}{l}
\rho_{11} \rho_{12} \\
\rho_{21} \rho_{22}
\end{array}\right]\left[\begin{array}{l}
\Delta \mathrm{p}_{\mathrm{D} 1} \\
\Delta \mathrm{p}_{\mathrm{D} 2}
\end{array}\right]
$$

\subsection{Artificial Bee Colony (ABC) Algorithm}

The Artificial Bee Colony [ABC] algorithm is used as an optimization search which simulates the intelligent foraging behavior of a honey bee swarm. Due to its simplicity and easy implementation, the $\mathrm{ABC}$ algorithm hascaptured much attention and has been applied to solve many practical optimization problems [14]. This method is found to be robust in solving even large and complex problems. The major advantage of $\mathrm{ABC}$ algorithm is that it conducts both global search and local search in each iteration and as a result the probability of finding the optimal parameters is significantly increased, which efficiently avoid local optimum to a large extent.

In the $\mathrm{ABC}$ algorithm, the artificial bees are grouped to three namely Employed bees, Onlookers and Scouts. A bee waiting on the dance area for making decision to choose a food source is called an Onlooker and a bee going to the food source visited by it previously is named an employed bee. A bee carrying out random search is called a Scout. Communication among bees about the quality of food sources is being achieved in the dancing area by performing waggle dance. In the ABC algorithm, first half of the colony consists of employed artificial bees and the second half constitutes the Onlookers. In other words, the number of employed bees is equal to the number of food sources around the hive. The employed bee whose food source is exhausted by the employed and onlooker bees becomes a scout. The main steps of the algorithm are given below [15]:

1. The search process starts with the random initialization of the bee population.

2. According to the objective functions examined, the nondominated solution sets are stored in the archive. The archive is used to store the best estimates of the Pareto front and is updated in each search iteration. The archive updating process contains two steps:

a. Firstly, the newly generated solution sets are combined with the non-dominated solution sets already stored in the archives. Then the dominated solutions are removed b. Secondly, if the archive maximal size is reached, a recurrent truncation method based on crowding distance is utilized to remove the least "promising" non-dominated solutions.

3. The diversity - based performance metric, given by $[0,1]$, of the solutions stored in the archive is calculated. $\alpha$ Estimates the level of uniformity in the distribution of solutions in the archive set, i.e., if $\alpha=1$ then the solutions are uniformly distributed, whereas with $\alpha=0.6$ we may approximate that $40 \%$ of the solutions are not evenly distributed. Note that with $\alpha=0$, the archive set is empty.

4. The current stage of food forage is determined according to the diversity of the archive set. Three stages or phases are distinguished: exploration, transition and exploitation.

Table 1. Bee colony structure based on diversity $\propto$

\begin{tabular}{ll}
\hline Bee type & Size \\
\hline Elite & $(\mathrm{i}-\alpha-\mathrm{s}) \mathrm{k}$ \\
Follower & $\alpha \mathrm{K}$ \\
Scout & $\mathrm{S} \mathrm{k} ;$ \\
& $(\mathrm{s}=1 /$ number of variables $)$ \\
\hline
\end{tabular}

5. The bee colony structure (i.e., ratios of elite, follower and scout bees) is adjusted according to $\alpha$. This adjustment aims at maximizing $\alpha$ (i.e., increase the distribution uniformity of the solutions). The goal is to make the solutions in the archive set evenly distributed. Note that the archive size $(\mathrm{K})$ is equal to the population size.

Table 1 lists the different bee type ratios which were devised according to the following considerations:

a. In general, the generated solution sets exhibit low diversity during the initial phase (i.e., $\alpha$ is low). In such cases the percentage of elite bees performing the waggle dance should be high (i.e., 1- $\alpha$ to be high) so that exploration is emphasized. As the search proceeds, the archive set eventually becomes more diversified; the elite bee ratio should then be decreased to facilitate local fine tuning.

b. According to the fitness (i.e., crowding distance) of individual solutions, $(1-\alpha-s) K$ of the bees are selected as elite ones. After that, waggle dance is performed by the elite bees.It is to be noted that the number of scout bees is fixed throughout the search.

6. The bees' search paths are subjected to variation. The scout bees use a polynomial mutation operator (promoting an increase in spread) to explore the search space further. The associated mutation probability is fixed. In contrast, elite and follower bees use the Simulated Binary Crossover (SBX) method to exploit the near-optimal generated solutions. The adjustment of the bee's search patterns is achieved through the automated tuning of SBX's distribution index. This is being performed in each iteration. The diversity-based performance metric is again utilized to drive this adjustment.

7. Then, based on the adjusted flying patterns, the bees carry out food foraging.

\subsection{ABC algorithm for $\mathrm{LFC}$ problem}

The following ABC algorithm [14] is adopted for the proposed study 
1. Initialize the food source position $X_{i}$ (solutions population) where $i=1,2 \ldots . D$

$$
\text { [ } \left.X_{i}=1,2,3 \ldots D\right]
$$

2. Calculate the nectar amount of the population by means of their fitness values using:

$$
f_{i} * t_{i}=1 /\left(1+o b j . \text { fun }_{\cdot i} J\right)
$$

Where $o b j$. fun . $i$ represents equation at solution $i$

3. Produce neighbor solution Vijfor the Employed bees by using equation

$$
V_{i j}=x_{i j}+\varphi_{i j}\left(x_{i j}-x_{k j}\right)
$$

Where $k=(1,2,3 \ldots . D)$ and $j=(1,2,3 \ldots N)$ are randomly chosen indexes $\Psi \varphi_{i j}$ is a random number between [-1,1] and evaluate them as indicated in step 2 .

4. Apply the greedy selection process for the Employed bees.

5. If all Onlooker bees are distributed, Go to step 9. otherwise, Go to the next step.

6. Calculate the probability values $P_{i}$ for the solution $X_{i}$ using by equation

$$
P i=\frac{f_{1} * t_{i}}{\sum_{n=1}^{N} f_{i} * t_{i}}
$$

7. Produce the neighbor solution $V_{i}$ for the Onlookers bee from the solution $X_{i}$ selected depending on $P_{i}$ and evaluate them.

8. Apply the greedy selection process for the Onlooker bees.

9. In $\mathrm{ABC}$ algorithm, providing that a position cannot be improved further through a predetermined number of cycles, then that food source is assumed to be abandoned. The value of pre determined number of cycles is an important control parameter of the ABC algorithm, which is called "limit" for abandonment. Assume that the abandoned source is $X_{i}$ and $J=(1,2,3, \ldots, N)$, then the Scout discovers a new food source to be replaced with $X_{i}$. Determine the abandoned solution for the Scout bees, if it exists, and replace it with a completely new solution $X_{i j}$ using the equation

$X_{i}^{j}=X_{\text {min }}^{j}+\operatorname{rand}(0,1) *\left(X_{\text {max }}^{j}-X_{\text {min }}^{j}\right)$

and evaluate them as indicated in step2.

10. Memorize the best solution attained so for.

11. If cycle=Maximum Cycle Number (MCN). Stop and print result, otherwise follow step 3 .

The Employed and Onlooker bees select new food sources in the neighborhood of the previous one in their memory depending on visual information and is based on the comparison of food-source positions. But, Scout bees, without any guidance while looking for a food-source position, explore a completely new food-source position. So Scout bees are characterized based on their behavior by low search costs and a low average in food-source quality. Occasionally, the Scouts bee can be fortunate to discover rich, entirely unknown food sources. In the case of artificial bee, the artificial Scouts bee could have the fast discovery of the group of feasible solutions as the task. Parameter tuning in meta-heuristic optimization algorithms influences the performances of the algorithm significantly. Divergences, becoming trapped in local extreme and time consumption are such consequences of setting the parameter improperly. The $\mathrm{ABC}$ algorithm has the advantage that it has few controlled parameters, since initializing populations "randomly" with a feasible region is sometimes cumbersome. The $\mathrm{ABC}$ algorithm does not depend on the initial population to be in a feasible region. Instead, its performance directs the population to the feasible region sufficiently.

\section{SIMULATION RESULTS AND OBSERVATIONS}

The optimal gains of Proportional plus Integral controllers $\left(\mathrm{K}_{\mathrm{P} 1}, \mathrm{~K}_{\mathrm{I} 1}, \mathrm{~K}_{\mathrm{P} 2}, \mathrm{~K}_{\mathrm{I} 2}\right)$, for two case studies are determined using $\mathrm{ABC}$ algorithm. These controllers are implemented in a interconnected multi unit two area power system without and with GT units for $1 \%$ step load disturbance in area 1. With the gain values, the cost function values, settling time and peak over/ under shoot for the frequency deviations in each area and tie-line power deviations for interconnected multi unit two area power system without and with GT units are found and tabulated in Table 2. The output responses of the two-area multi unit interconnected system are shown in fig 5 and fig 6 and from that it is evident that the dynamic responses have improved significantly with the use of GT units.

From the Tabulations, it can be found that the controller designed for two area thermal reheat power system with GT have not only reduces the cost function but also ensure better stability, less over/under shoot and faster settling time when compared with the controller designed for the two area multi unit thermal reheat power system without GTunit.
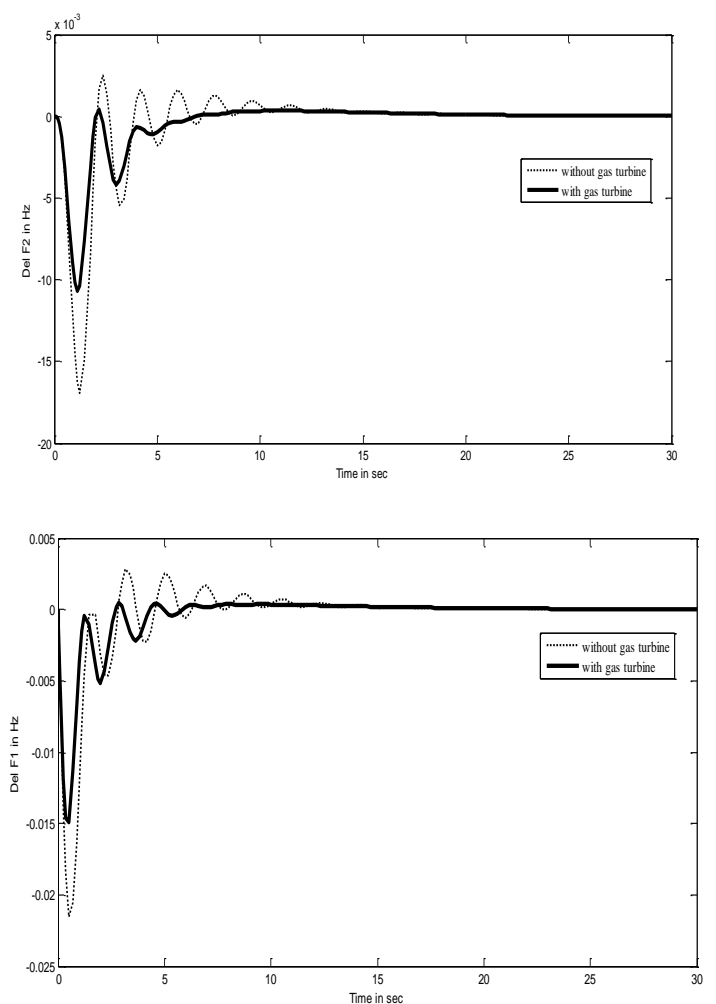


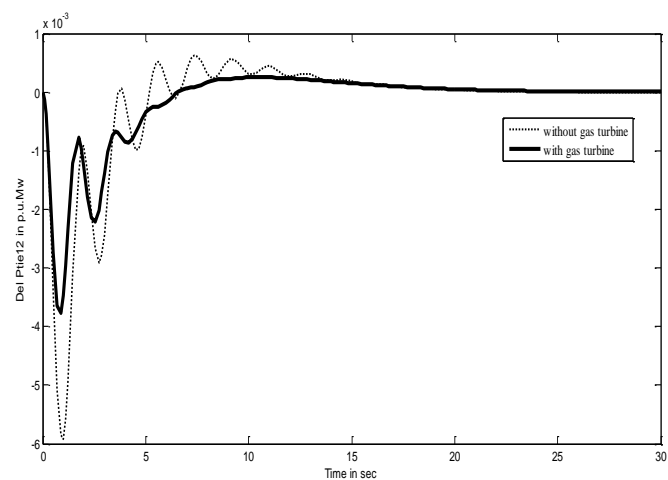

Fig 5. Dynamic responses of the frequency deviations and tie-line power deviation considering a step load disturbance of $0.01 \mathrm{p}$. in area 1
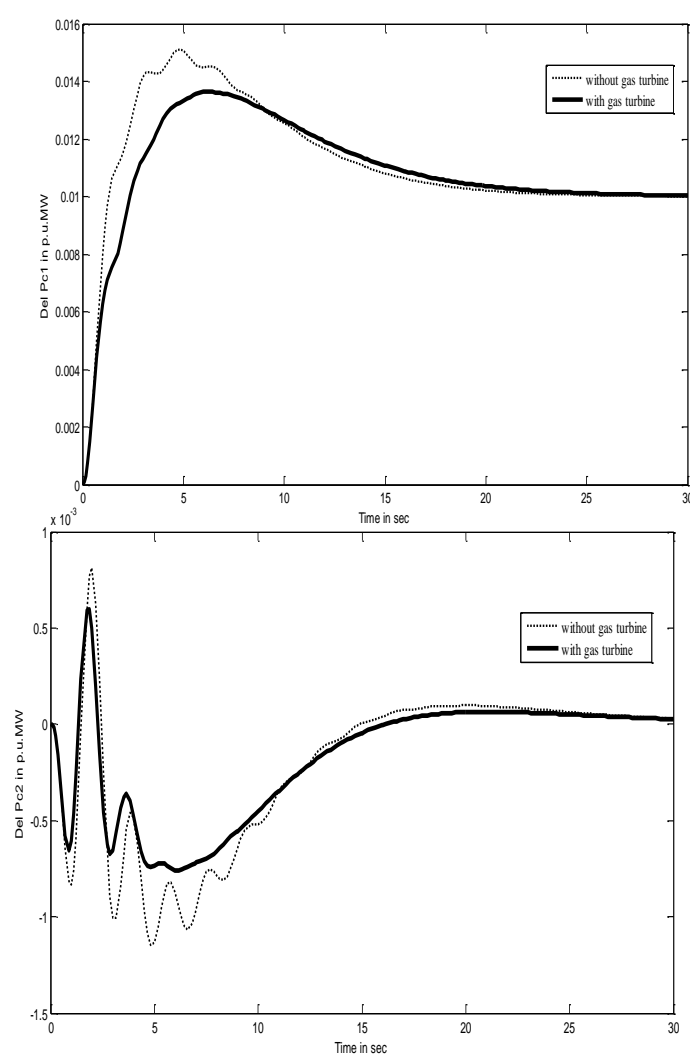

Fig 6. Dynamic responses of the control input deviations considering a step lo disturbance of 0.01 p.u in area 1
Table. 2. Comparison of the system performance for the two case studies

\begin{tabular}{|c|c|c|c|c|c|c|}
\hline \multirow{2}{*}{$\begin{array}{c}\text { Two area } \\
\text { interconnected } \\
\text { power system } \\
\text { with } \\
\text { Proportional } \\
\text { plus Integral } \\
\text { controller using } \\
\text { Area } \\
\text { Requirement } \\
(\mathrm{AR}) \text { criterion } \\
\end{array}$} & \multicolumn{3}{|c|}{$\begin{array}{c}\text { Setting time }\left(\tau_{s}\right) \\
\text { in sec }\end{array}$} & \multicolumn{3}{|c|}{ Peak over / under shoot } \\
\hline & $\Delta \mathbf{F}_{1}$ & $\Delta \mathbf{F}_{2}$ & $\Delta \mathbf{P}_{\text {tie }}$ & $\begin{array}{c}\Delta \mathbf{F}_{1} \\
\text { in } \mathbf{H z}\end{array}$ & $\begin{array}{c}\Delta F_{2} \\
\text { in } \mathbf{H z}\end{array}$ & $\begin{array}{c}\Delta \mathbf{P}_{\text {tie }} \\
\text { in p.u.MW }\end{array}$ \\
\hline $\begin{array}{l}\text { Without Gas } \\
\text { Turbine unit }\end{array}$ & 12.51 & 13.66 & 14.48 & 0.0215 & 0.0169 & 0.0059 \\
\hline $\begin{array}{l}\text { With Gas } \\
\text { Turbine unit }\end{array}$ & 8.523 & 9.522 & 10.53 & 0.0149 & 0.0102 & 0.0038 \\
\hline
\end{tabular}

\section{CONCLUSION}

In this paper, the responses of a two area multi unit interconnected thermal reheat power system without and with GT units have been studied. The Proportional plus Integral gain setting have been optimized using $\mathrm{ABC}$ algorithm. Gas Turbine units are connected in area 1 and the responses show that they are capable of consuming the oscillations in frequency deviations, tie-line power deviations and control input requirements of the power system. Further GT units reduce the over shoot and setting time of the output responses. Hence, it may be concluded that the GT units are efficient and effective for improving the dynamic performance of load frequency control of interconnected power system than that of the system without GT unit.

\section{ACKNOWLEDGMENT}

The authors wish to thank the authorities of Annamalai University, Annamalainagar, Tamilnadu, India for the facilities provided to prepare this paper.

\section{REFERENCES}

[1] H. Shayeghi, H.A. Shayanfar, A. Jalili, "Load frequency control strategies: A state-of-the-art survey for the researcher", Energy Conversion and Management, Vol. 50, No.2, 2009, pp. 344-353.

[2] I.P. Kumar, D.P. Kothari, "Recent Philosophies of automatic generation control strategies in power systems" IEEE Transactions on Power System, Vol. 20, No.1, 2005 pp. 346-347.

[3] Ross CW, Green TA, "Dynamic Performance evaluation of a computer - controlled electric power", IEEE Transactions on Power Apparatus system, Vol.91, 1972, pp.1158-1165.

[4] Jaleeli N, Vanslyck LS, 'NERC's New Control Performance Standards, IEEE Transaction Power on System, Vol.14, 1998, pp. 1092-1099. 
[5] Sasaki T, Enomoto K. "Statistical and dynamic analysis of generation control performance standards." IEEE Transactions on Power System, Vol. 17, 2002, pp. 476481.

[6] Soon Kiat Yee, JovicaV.Milanovic, F.M.Michael Hughes, "Overview and comparative Analysis of Gas Turbine Models for System Stability Studies", IEEE Transactions on Power Systems, Vol.23, No.1, 2008, pp. 108-118.

[7] R.Jayanthi, I.A.Chidambaram, "Load-Frequency control Assessment using Restoration index with Artifical Bee colony Algorithm for interconnected Power System with Disturbance Accomodation controller", International Journal of Computer Applications, Vol 39, No 6, 2012, pp.24-36.

[8] Barsali, S., D.Polio, A.Pratico, R.Salvati, M.Sforna, "Restoration islands supplied by gas turbine", Electrical Power System Research, Vol. 78, 2008, pp.20042010.

[9] Nagpal. M., A.Moshref, G.K Morision, P.Kundur, "Experience with Testing and modeling of gas turbine", Proceedings of the IEEE/PES 2001 Winter Meeting, Columbus USA, 2001, pp.652-656.

[10] Ghoshal, "Application of Ga/GA-SA based fuzzy automatic control of multi-area thermal generating system", Electric Power System Research, Vol. 70, 2004, pp. 115-127.

[11] P.J. Angeline, "Using Selection to Improve Particle Swarm Optimization", Proceeding IEEE International Conference of Evolutionary Computing, 1998, pp 84-90.

[12] D. Karaboga, "An Idea Based on Honey Bee Swarm for Numerical Optimization", Technical Report - TR06, Erciyes University, Turkey, 2005.

[13] D. Karaboga, B. Basturk, "On the Performance of Artificial Bee Colony (ABC) Algorithm, Applied Soft Computing, Vol.8, No.1, 2008, pp. 687-697.

[14] D. Karaboga, B. Basturk, "Artificial Bee Colony (ABC) Optimization Algorithm for solving constrained Optimization problems", LNCS: Advances in Soft computing foundations of Fuzzy logic and soft computing, Vol. 4529, 2007, pp. 789-798

[15] DervisKaraboga, BahriyeAkay, "A comparative study of Artifical Bee Colony Algorithm". Applied Mathematics and Computation, Vol. 214, 2009, pp.108-132.

[16] I.A. Chidambaram, S. Velusami, "Design of decentralized biased controllers for load-frequency control of interconnected power systems". International Journal of Electric Power Components and Systems, Vol.33, No.12,2005, pp.1313-1331.

\section{APPENDIX}

\section{(i) Data for Thermal Reheat Power System [16]}

Rating of each area $=2000 \mathrm{MW}$, Base power $=2000 \mathrm{MVA}$, $\mathrm{f}^{\circ}=60 \mathrm{~Hz}, \quad \mathrm{~K}_{\mathrm{p} 1}=\mathrm{K}_{\mathrm{p} 2}=120 \mathrm{~Hz} /$ p.u. $\mathrm{MW}$

$\mathrm{T}_{\mathrm{p} 1}=\mathrm{T}_{\mathrm{p} 2}=20 \mathrm{sec}, \quad \mathrm{T}_{\mathrm{t} 1}=\mathrm{T}_{\mathrm{t} 2}=\mathrm{T}_{\mathrm{t} 3}=\mathrm{T}_{\mathrm{t} 4}=0.3 \mathrm{sec}$,

$\mathrm{T}_{\mathrm{g} 1}=\mathrm{T}_{\mathrm{g} 2}=\mathrm{T}_{\mathrm{g} 3}=\mathrm{T}_{\mathrm{g} 4}=0.08 \mathrm{sec}, \quad \mathrm{K}_{\mathrm{r} 1}=\mathrm{K}_{\mathrm{r} 2}=\mathrm{K}_{\mathrm{r} 3}=\mathrm{K}_{\mathrm{r} 4}=0.5$, $\mathrm{T}_{\mathrm{r} 1}=\mathrm{T}_{\mathrm{r} 2}=\mathrm{T}_{\mathrm{r} 1}=\mathrm{T}_{\mathrm{r} 2}=10 \mathrm{sec}, \quad \mathrm{R}_{1}=\mathrm{R}_{2}=\mathrm{R}_{3}=\mathrm{R}_{4}=2.4 \mathrm{~Hz} / \mathrm{p} . \mathrm{u}$ $\mathrm{MW}, \mathrm{a}_{12}=-1, \mathrm{~T}_{12}=0.545$ p.u MW/Hz, $\beta_{1}=\beta_{2}=0.425$ p.u. $\mathrm{MW} / \mathrm{Hz}, \Delta \mathrm{P}_{\mathrm{D} 1}=0.01$ p.u $\mathrm{MW}$

\section{(ii) Data for GT unit}

$\mathrm{T}_{\mathrm{GH}}=0.2 \mathrm{sec}, \mathrm{X}_{\mathrm{G}}=0.6 \mathrm{sec}, \mathrm{Y}_{\mathrm{G}}=1.1 \mathrm{sec} \mathrm{C}_{\mathrm{g}}=1$, $\mathrm{b}_{\mathrm{g}}=$ $0.049 \mathrm{sec}, \mathrm{T}_{\mathrm{F}}=0239 \mathrm{sec} \mathrm{T}_{\mathrm{CR}}=0.01 \mathrm{sec}, \mathrm{T}_{\mathrm{CD}}=0.2 \mathrm{sec}$

\section{AUTHORS' PROFILE}

P.Venkatasubramanian received Bachelor of Engineering in Electrical and Electronics Engineering (2000), Master of Engineering in Power System Engineering (2006) and he is working as Assistant Professor in the Department of Electrical Engineering, Annamalai University, Annamalainagar, Tamilnadu, India. He is currently working towards his Ph.D degree. His research are in include Power System operation and control, Power Electronic applications to Power Sytem.

S.Abraham Lincon obtained his B.E degree is Electronics and Instrumentation Engineering (1984), Master of Engineering in Power System Engineering (1987), Master of Engineering in Process Control Instrumentation (2000), Ph.D in Instrumentation Engineering (2007) from the Annamalai University, Annamalainagar. Presently he is working as a professor of the Department of Instrumentation Engineering in Annamalai University. His areas of research are Process Control, Fault Detection and Diagnosis and Multivariable Control. 